\title{
How much 'lived experience' is enough? Understanding mental health lived experience work from a management perspective
}

\author{
Helena Roennfeldt ${ }^{1,2,3}$ MSW, Senior Research Officer \\ Louise Byrne ${ }^{1,2} \mathrm{PhD}$, Fulbright Fellow \\ ${ }^{1}$ Central Queensland University, School of Nursing, Midwifery and Social Sciences, 700 Yaamba Road, \\ Norman Gardens, Qld 4701, Australia. \\ ${ }^{2}$ Present address: RMIT University, School of Management, 124 La Trobe Street, Melbourne, Vic. 3000 , \\ Australia. Email: louise.byrne3@rmit.edu.au \\ ${ }^{3}$ Corresponding author. Email: helena.roennfeldt@rmit.edu.au
}

\begin{abstract}
.
Objective. The aim of this study was to explore management understanding of the lived experience required for designated lived experience or peer roles within mental health.

Method. This qualitative study used semi-structured interviews and one focus group with 29 participants employed in diverse management roles from the public and not-for-profit health and community sector in Queensland, Australia.

Results. The findings indicate a lack of consensus in defining 'lived experience', including what lived experience is required to be eligible for designated roles. Although some participants were clear on what designated roles added to the workforce, uncertainty and attempts to avoid stigma led to some participants questioning the need for designated roles.

Conclusion. This study suggests the ongoing expansion of the lived experience workforce is affected by challenges in defining 'lived experience' as a requirement for designated roles and fears regarding stigmatised identities.
\end{abstract}

What is known about the topic? In the mental health sector, opportunities and challenges exist in attempting to effectively incorporate the emerging lived experience or peer workforce. Research has highlighted the need for support from senior management, the need for role clarity and the risk of 'othering' for the lived experience workforce.

What does this paper add? This paper responds to the gap in existing research on the experiences of management in defining and articulating their understanding of lived experience and potential impact of uncertainty and inconsistency in understanding for the lived experience workforce.

What are the implications for practitioners? This study identifies the need to strengthen management understanding of lived experience to facilitate ongoing development of lived experience roles.

Additional keywords: identity, mental health services, peer work, stigma.

Received 25 November 2019, accepted 15 February 2020, published online 5 August 2020

\section{Introduction}

As an emerging workforce, evidence suggests lived experience or peer workers are at least as effective as traditional mental health workers in supporting consumers ${ }^{1}$ and have unique benefits in facilitating engagement, promoting hope, activating self-management, combating stigma and enabling wellbeing., 2,3 Lived experience work differs from traditional mental health roles because the key criterion is the use of lived experience and knowledge obtained through experiences of mental health challenge, service use and recovery. ${ }^{4,5}$ Consequently, lived experience workers draw on expertise through experience to offer a distinct way of working. 3,6
Increasingly, the inclusion of people with lived experience is seen as best practice within mental health service delivery. ${ }^{7,8}$ This represents significant progress from the historic position of people with lived experience as 'outside' the mental health system. ${ }^{9-11}$ This changing landscape provides new opportunities and challenges of inclusion within mainstream service delivery for both lived experience workers and service providers. ${ }^{12}$

Employment of lived experience workers is also considered vital in transitioning organisations towards a more recoveryoriented approach. ${ }^{13,14}$ Personal choice and self-direction are key to recovery, which also includes themes of hope, identity, meaning, empowerment and connection. ${ }^{15}$ Recovery often 
clashes with a traditional 'medical model' approach, which emphasises practitioner-led treatment and often focuses on pathology rather than relationship. ${ }^{16}$ Similarly, the potential for co-option of lived experience roles arises through tensions between lived experience perspectives and traditional service delivery. ${ }^{17,18}$ Co-option describes the process of assimilation of a non-conforming group into an established group, ${ }^{19}$ which, for lived experience workers, results in 'a drift towards more traditional service practices'. ${ }^{20}$

Designated lived experience positions are questioned by some as contributing to stigmatised professional roles, reinforcing a person's identification with their experience of mental illness. ${ }^{21}$ Issues with designated roles are further compounded by challenges in determining who qualifies as having relevant lived experience and whether the lived experience that is required changes within different contexts (e.g. community versus in-patent settings). ${ }^{18}$ Generally, organisations have struggled with how to define and measure lived experience, ${ }^{22}$ questioning what lived experience counts, ${ }^{23}$ with varying emphasis on diagnosis, service use and the life-changing impact of the diagnosis. $^{22}$ This lack of a shared understanding of what lived experience is required and how it can be used within lived experience roles ${ }^{18}$ may provide an explanation for the lack of role clarity for lived experience workers. ${ }^{24}$

The role of management is critical in the effective employment of lived experience workers, ${ }^{25}$ with previous research highlighting the need for support from senior management, as well as the need for role clarity and the risk of 'othering' for the lived experience workforce. ${ }^{26-28}$ 'Othering' identifies those that are thought to be different from the mainstream and may include negative attribution to reinforce positions of dominance. ${ }^{29}$

This study explored the role of management regarding the lived experience workforce in public and not-for-profit health and community sectors. For the purposes of this study, 'management' included executive-level staff, those with responsibility for the allocation of staffing budgets and line management or supervisory responsibilities. In this paper, we examine the views of management in relation to defining lived experience roles and the value and risk of designated roles.

Because of the subject of this research, it is important to note that the researchers identify as having personal experience of mental health challenges, service use and periods of healing, and primarily work within designated lived experience roles.

\section{Methods}

\section{Research design}

This was a qualitative study using grounded theory methods. In line with grounded theory methods, both interviews and focus group began with very broad questions regarding participants' experiences with the lived experience workforce. Grounded theory allows the data to guide the direction of the research, ${ }^{30}$ and this approach is regarded as particularly useful when little is known about an area, ${ }^{31}$ as is the case with management perspectives on lived experience work.

\section{Ethics approval}

Ethics approval for the study was granted by the Central Queensland University Human Ethics Committee (18 December
2015; H15/11-262) and the Prince Charles Hospital Human Research Committee (20 September 2016; HREC/16/QPCH/ 298). Before participants were contacted, letters of approval for the study were provided by relevant organisations (i.e. those taking part in the study). Participants were provided with an overview of the study purpose and informed that all participation was completely voluntary. All participants provided informed written consent, and no incentives were provided. Participant confidentiality was maintained by deidentifying all data, replacing participant names with pseudonyms and removing or coding all identifying information. Coded transcripts are stored separately to identifiable materials and will be secured in locked, passwordprotected files until 5 years after the last publication from the data.

\section{Recruitment and participation}

Participants included people employed in traditional (nondesignated management roles), including nurses, psychiatrists, psychologists, social workers, occupational therapists, executive administrators and other health professionals, and designated lived experience management participants employed in both the public and not-for-profit sectors. Participants were purposely sampled to represent a wide range of perspectives and levels of experience with lived experience employment. For some very large organisations, such as district health services and not-for-profit organisations with diverse services across Queensland, more than one employee from different services within the organisation may have taken part in the study.

In all, 29 people participated in the study; 16 were employed within the non-government sector and 13 were employed in public health organisations. Participants were predominantly employed in traditional roles $(n=19)$, with fewer employed in designated 'lived experience management' positions $(n=8)$ and 'carer' management positions $(n=2)$. Of the organisations represented by participants, six had no history employing peer workers, 13 had a small number of peer staff and 10 had significant experience with peer employment.

\section{Procedure}

The study comprised 24 in-depth, semistructured interviews and one focus group $(n=6)$, with one focus group participant also choosing to be interviewed. The focus group represented participants from a large district health service and was included to allow different types of themes to emerge within a group context. Interviews were conducted either face to face or over the telephone. All interviews and focus group were audio recorded and transcribed verbatim.

Congruent with grounded theory methods, interviews were conducted until saturation of responses occurred (i.e. no new themes were emerging from the data). ${ }^{32}$

\section{Data collection and analysis}

Transcripts of interviews were analysed initially using an opencoding method ${ }^{33}$ to identify key concepts in the data.

After the initial line-by-line analysis was completed, the research team met to consider the properties of concepts, identify categories and unify coding. All data were entered into NVivo 11 (QSR International, Melbourne, Vic., Australia) to facilitate data handling and the sharing of data across the research team. 


\section{Results}

Two overriding themes emerged from the research: (1) determining the 'lived experience' required for lived experience roles; and (2) querying the need for designated roles. Determining the lived experience required for designated roles related to uncertainty regarding what lived experience counts and how 'recovered' someone needed to be in order to be effective within a lived experience role. Questioning the need for designated roles revealed tensions for participants who feared that designated roles potentially contributed to stigma and 'othering'.

\section{What lived experience counts?}

Defining lived experience posed challenges for participants in relation to understanding the level or type of experience that qualifies as 'enough' lived experience. For some participants, there was uncertainty and resistance to the idea of measuring the amount of lived experience someone had:

Does it mean you have to have used a public mental health service, does it mean you just have to have had a diagnosable mental health condition, does it mean you could've had 6 or 12 months of really struggling, what actually qualifies you for having lived experience? (Reginald)

What do we actually mean by lived and living experience? People don't want to go 'well this is the threshold that you've gotta meet in order to have the card for lived experience'. (Pippa)

Other participants discussed the need for the lived experience worker to have received a 'significant' diagnosis that has a major impact on an individual's life. The diversity of views also raised the question of who is determining and defining people's experience:

...it means different things to different people. It was not always an easy task to define what lived experience was in the context of lived experience roles. (Pippa)

\section{Recovered enough?}

Compounding these definitional uncertainties were questions related to how 'recovered' someone needed to be in order to work effectively as a lived experience worker. Some participants believed that reaching a level of recovery was necessary:

I think there needs to be a reasonable level of recovery. (Byron)

I think you have to be really well, as the peer support [lived experience] worker, really well healed in your recovery journey and what I suspect has been the problem is people thought they were far enough along their own recovery journey to do this work. But once you get into the role and you're kind of reminded of what you've been through and you probably have all sorts of triggers throughout the course of the work. (Oscar)

In contrast, for other participants, measuring how recovered someone was did not align with their understanding of recovery:

I don't think it's actually about a level of recovered or this idea that recovery is linear and that it somehow maps to your ability to do work. (Matt)
... who can determine what's 'recovered enough' and what isn't? I mean a lot of people are in recovery and they have relapse, so relapse's a normal part of life, so we all have ups and downs. But you know just saying 'you're not recovered enough to do this job' is a load of bullshit. (Sam)

\section{Need for designated roles}

The employment of designated roles was weighed against ideas of shared humanity with participants questioning, 'don't we all have lived experience?':

I think every person in the world has a lived experience and a lived experience might be growing up and being a mum and a dad, your lived experience mightn't contain a 'mental health issue' but you've still got a lived experience. (Bruce)

It's really valuable to employ people with a range of lived experiences, with a lived experience of mental health challenge and other lived experiences as well, other challenges. In our workplace here we encourage what we'd call human work, so we want our workers to be humans... rather than go down that road of having demarcated lived experience roles. (Calvin)

Similarly, participants raised concerns that identified roles contributed to stigma and discrimination:

I think of workers within our workforce who've moved from lived experience roles into non-designated roles, but that can never be unknown about them. And I'm not suggesting that they would want it to be unknown, but I think it's got to be a pretty healthy organisation for someone to not feel that there's any career limiting elements around any of that, so I think people do recognise that you've opened that door, you can't close that door. (Penny)

... so in an ideal world I would prefer that we didn't have to label people lived experience workers. I think there's probably a raft of very good workers out there who don't particularly want to spend their day being called a lived experience worker and don't particularly want to spend their day reciting their story or tell everybody that they had a mental health issue. (Josh)

However, other participants believed designated roles were needed to challenge stigma:

...there's really something about challenging stigma that is about getting out there and that really changes perspectives, from the people who we provide support to, to ourselves, to our co-workers, to society at large, that you just can't achieve in the same way if you haven't been there and you're not wearing that [lived experience] tag. (Matt; lived experience management role)

In addition to potentially challenging stigma, some participants described the lived experience role as significantly different from other roles:

...lived experience workers have an ability to be more of an equal with the consumers and carers that we work with. (Reginald) 
The lived experience roles are very different and that's my concern, if we're diluting these roles and at times, I think in some situations we are losing that real 'lived experience'. (Molly)

Some participants in designated roles expressed a fear of the uniqueness of lived experience roles being 'co-opted' by more dominant practice:

I definitely have personal experiences of feeling like I started to look like I'd been co-opted or wondering if I should start doing it like everybody else. (Jane; lived experience management role)

Other participants struggled to articulate the difference but alluded to a hard to define 'extra' that lived experience workers brought to the roles:

The way we're hiring lived experience professionals is we think they're everything that everybody else is and a bag of chips. (Matt)

I do think lived experience workers bring an extra 'X factor' that is important. (Penny)

\section{Discussion}

Unique to this study is the focus on management perspectives. Management perspectives are considered significant because of managers' positions as leaders within organisations and their influence on the employment of lived experience workers in mental health services. ${ }^{33}$ The findings of this study describe challenges for management in articulating an understanding of 'lived experience' required for designated roles. This uncertainty affected the participants' motivation to employ lived experience workers.

These findings reflect previous attempts to define lived experience within the literature, which have variously focused on experiences of diagnosis, service use and life-changing effects of mental health challenges. ${ }^{22,23}$ In contrast, other research indicates that relevance may be more related to membership within a target population, as identified in a study of the lived experience workforce with veterans ${ }^{23}$ or relevant experiences for specific programs, such as smoking cessation. ${ }^{34}$ It is of note that most participants in the present study associated lived experience as direct or personal experience as opposed to descriptions within some literature of lived experience as inclusive of the experience of family members or carers. ${ }^{35,36}$ The ambiguity in this study reinforces the need for greater consensus in defining and determining relevant lived experience in the context of designated roles. ${ }^{22}$

Given the centrality of lived experience to designated roles, confusion related to what experience is relevant may compound issues of role clarity previously identified in the literature. $^{5,25,27,37}$ Further, uncertainty and questioning by some participants about who determines relevant lived experience underline the directive that the lived experience workers set their own parameters about what is relevant and define themselves as a workforce. ${ }^{38,39}$

Participants held divergent views of how recovered someone needed to be to in order to be effective, with some participants attributing inadequate levels of recovery as the 'problem' with lived experience roles. Other participants stressed that recovery was an ongoing process, and the individual and highly personalised nature of recovery made an external assessment of recovery fraught. ${ }^{40}$ This disagreement in perspectives reinforces the need for management understanding of personal recovery in supporting the lived experience workforce ${ }^{41}$ and confirms potential confusion related to 'how recovered' lived experience workers needed to be in order to be effective. ${ }^{42}$ These contrasting perspectives may reflect previous research uncovering paternalistic attitudes within health professionals, ${ }^{43}$ highlighting the importance of privileging first-person accounts of recovery and including lived experience-led recovery training. ${ }^{44}$

The challenges for lived experience workers in retaining their lived experience perspective within traditional settings and the risks of co-option and acculturation have been previously identified. ${ }^{17}$ This was echoed in the present study by one participant in a designated management role, noticing that her role began to be indistinguishable from non-designated roles. Difficulty for participants in articulating the uniqueness of lived experience roles may contribute to an experience of co-option of the lived experience role by minimising lived experience workers' capacity to offer a unique lived experience perspective. $^{45}$

This study specifically identified that some people employed in management roles are resistant to employing designated lived experience roles because they do not understand how to define lived experience and are fearful of potential stigma associated with designated roles. Fears that designated roles contribute to stigma suggest that experiential knowledge and identification as a lived experience worker are associated with a lower value status and stigmatised identity. ${ }^{21,41}$ Some participants expressed the desire for an ideal work environment in which designated roles would not be needed. Although this objective was driven by a desire to resist lived experience being perceived as 'other', 46 it is unclear from responses how stigma would be addressed without the use of lived experience roles or how lived experience, if conflated with broader human experiences, informs practice.

In contrast, some participants acknowledged the prevalence of stigma and suggested the most effective way to challenge stigma is by having lived experience workers. These participants cited the need for lived experience workers to challenge stigma by publicly identifying with their experience of diagnosis and system use. This perspective is reinforced by significant research that supports public disclosure and the role of lived experience in addressing mental health stigma. ${ }^{47-50}$

The variety of perspectives by management in this study underscore the risks of lived experience roles being subsumed within the mainstream workforce if mental health lived experience as a unique form of knowledge is not understood and valued. $^{5,41}$

\section{Limitations}

This qualitative study is limited by the relatively small numbers and by the fact it was conducted in only one state in Australia; therefore, the findings may not be generalisable to other countries or regions. Further, this study reported on management broadly, and comparison of different disciplines and different work settings (non-governmental organisations, public health) 
may provide further insight into divergent management understanding. In addition, including the perspectives of the lived experience workforce may assist in developing strategies within the workplace that support valued status and role clarity of lived experience work.

\section{Conclusion}

Uncertainties in defining lived experience, and concerns posed by stigmatised identities, have added to questions about the need for designated lived experience roles. More thorough research is warranted to understand the impact of these diverse perspectives and facilitate ways to resolve contention and assist in a better understanding of lived experience roles.

\section{Competing interests}

The authors have no competing interests to report.

\section{Acknowledgement}

This research was funded by the Queensland Mental Health Commission.

\section{References}

1 Repper J, Carter T. A review of the literature on peer support in mental health services. J Ment Health 2011; 20: 392-411. doi:10.3109/ 09638237.2011.583947

2 Salzer MS, Schwenk E, Brusilovskiy E. Certified peer specialist roles and activities: results from a national survey. Psychiatr Serv 2010; 61: 520-3. doi:10.1176/ps.2010.61.5.520

3 Daniels AS, Bergeson S, Myrick KJ. Defining peer roles and status among community health workers and peer support specialists in integrated systems of care. Psychiatr Serv 2017; 68: 1296-8. doi:10. 1176/appi.ps.201600378

4 Chinman M, George P, Dougherty RH, Daniels AS, Ghose SS, Swift A, Delphin-Rittmon ME. Peer support services for individuals with serious mental illnesses: assessing the evidence. Psychiatr Serv 2014; 65: 429-41. doi:10.1176/appi.ps.201300244

5 Chapman S, Blash L, Chan K, Mayer K, Kogler V, Spetz J. Education, certification, and roles of peer providers: lessons from four states. San Francisco: UCSF Health Workforce Research Center on Long-Term Care; 2015.

6 Scholz B, Bocking J, Happell B. Improving exchange with consumers within mental health organizations: recognizing mental ill health experience as a 'sneaky, special degree'. Int J Ment Health Nurs 2018; 27: 227-35. doi:10.1111/inm.12312

7 Voronka J. Turning mad knowledge into affective labor: the case of the peer support worker. Am Q 2017; 69: 333-8. doi:10.1353/aq.2017.0029

8 Gagne CA, Finch WL, Myrick KJ, Davis LM. Peer workers in the behavioral and integrated health workforce: opportunities and future directions. Am J Prev Med 2018; 54(6 Suppl 3), S258-66. doi:10.1016/ j.amepre.2018.03.010

9 Pinches A. What the consumer movement says about recovery. 2004. Available at: https://www.ourcommunity.com.au/files/OCP/PinchesRecovery.pdf [verified 11 June 2020].

10 Ostrow L, Adams N. Recovery in the USA: from politics to peer support. Int Rev Psychiatry 2012; 24: 70-8. doi:10.3109/09540261.2012.659659

11 Davidson L, Bellamy C, Guy K, Miller R. Peer support among persons with severe mental illnesses: a review of evidence and experience. World Psychiatry 2012; 11: 123-8. doi:10.1016/j.wpsyc.2012.05.009

12 Gillard S, Foster R, Gibson S, Goldsmith L, Marks J, White S. Describing a principles-based approach to developing and evaluating peer worker roles as peer support moves into mainstream mental health services. Ment Health Soc Inclusion 2017; 21: 133-43. doi:10.1108/MHSI-03-2017-0016
13 Department of Health. The fifth national mental health and suicide prevention plan. 2017. Available at: https://wwwl.health.gov.au/internet/main/publishing.nsf/Content/mental-fifth-national-mental-healthplan [verified 11 June 2020].

14 Health Workforce Australia. Mental health peer workforce study. 2014. Available at: http://www.mhcsa.org.au/wp-content/uploads/ 2018/12/HWA-Mental-health-Peer-Workforce-Study.pdf [verified 11 June 2020].

15 Leamy M, Bird V, Le Boutillier C, Williams J, Slade M. Conceptual framework for personal recovery in mental health: systematic review and narrative synthesis. Br J Psychiatry 2011; 199: 445-52. doi:10. 1192/bjp.bp. 110.083733

16 Byrne L, Happell B, Reid-Searl K. Lived experience practitioners and the medical model: world's colliding? J Ment Health 2016; 25: 217-23. doi: $10.3109 / 09638237.2015 .1101428$

17 Pilgrim D. Protest and co-option - the voice of mental health service users. In: Bell A, Lindley P, editors. Beyond the water towers: the unfinished revolution in mental health services 1985-2005. London: The Sainsbury Centre for Mental Health; 2005. pp. 17-26. Available at https://www.centreformentalhealth.org.uk/sites/default/files/beyond_ the_water_towers.pdf [verified 11 June 2020].

18 Gillard SG, Edwards C, Gibson SL, Owen K, Wright C. Introducing peer worker roles into UK mental health service teams: a qualitative analysis of the organisational benefits and challenges. BMC Health Serv Res 2013; 13: 188. doi:10.1186/1472-6963-13-188

19 Gamson W. Movement impact on cultural change. In: S Pfohl, A Van Wagenen, P Arend, A Brooks, D Leckaby, editors. Culture, power and history: studies in critical sociology. Boston, MA: Brill Publishers; 2005. pp. 103-125.

20 Mead S, MacNeil C. Peer support: what makes it unique. Int J Psychosoc Rehabil 2006; 10: 29-37.

21 Hutchinson A, Lovell A. Participatory action research: moving beyond the mental health 'service user' identity. J Psychiatr Ment Health Nurs 2013; 20: 641-649. doi:10.1111/jpm.12001

22 Silver J, Nemec PB. The role of the peer specialists: unanswered questions. Psychiatr Rehabil J2016; 39: 289-91. doi:10.1037/prj0000216

23 Clark C, Barrett B, Frei A, Christy A. What makes a peer a peer? Psychiatr Rehabil J 2016; 39: 74-6. doi:10.1037/prj0000147

24 Cronise R, Teixeira C, Rogers ES, Harrington S. The peer support workforce: results of a national survey. Psychiatr Rehabil J 2016; 39: 211-21. doi:10.1037/prj0000222

25 Byrne L, Roennfeldt H, O'Shea P, Macdonald F. Taking a gamble for high rewards? Management perspectives on the value of mental health peer workers. Int J Environ Res Public Health 2018; 15: 746. doi:10. 3390/ijerph15040746

26 Berry C, Hayward MI, Chandler R. Another rather than other: experiences of peer support specialist workers and their managers working in mental health services. J Public Ment Health 2011; 10: 238-49. doi:10. 1108/17465721111188269

27 Jenkins S, Chenneville T, Salnaitis C. Are peer specialists happy on the job? Psychiatr Rehabil J 2018; 41: 72-5. doi:10.1037/prj0000259

28 McLean J, Biggs H, Whitehead I, Pratt R, Maxwell M. Evaluation of the Delivering for Mental Health Peer Support Worker pilot scheme. Edinburgh: Scottish Government Social Research; 2009. Available at: www.scotland.gov.uk/Resource/Doc/291864/0089933.pdf [verified 26 June 2020].

29 Johnson JL, Bottorff JL, Browne AJ, Grewal S, Hilton BA, Clarke H. Othering and being othered in the context of health care services. Health Commun 2004; 16: 255-71. doi:10.1207/S15327027HC1602_7

30 Corbin J, Strauss A. Basics of qualitative research: techniques and procedures for developing grounded theory. 3rd edn. London: SAGE Publications; 2008.

31 Charmaz K. Constructing grounded theory. 2nd edn. London: SAGE Publications; 2014. 
32 Glaser BG, Strauss AL. The discovery of grounded theory. New York: Adline de Gruyter; 1967.

33 Byrne L, Roennfeldt H, Wang Y, O'Shea P. 'You don't know what you don't know': the essential role of management exposure, understanding and commitment in peer workforce development. Int J Ment Health Nurs 2019; 28: 572-81. doi:10.1111/inm.12562

34 Dickerson F, Savage CL, Schweinfurth LA, Goldberg RW, Bennett M, Dixon L, Daumit G, Chinman M, Lucksted A. The experience of peer mentors in an intervention to promote smoking cessation in persons with psychiatric illness. Community Ment Health J 2016; 52: 416-23. doi:10. 1007/s10597-015-9967-0

35 Barkway P, Mosel K, Simpson A, Oster C, Muir-Cochrane E. Consumer and carer consultants in mental health: the formation of their role identity. Adv Ment Health 2012; 10: 157-68. doi:10.5172/jamh.2011. 10.2.157

36 Ning L. Building a 'user driven' mental health system. Adv Ment Health 2010; 9: 112-15. doi:10.5172/jamh.9.2.112

37 Hurley J, Cashin A, Mills J, Hutchinson M, Graham I. A critical discussion of peer workers: implications for the mental health nursing workforce. J Psychiatr Ment Health Nurs 2016; 23: 129-35. doi:10. 1111/jpm. 12286

38 Mead S, Hilton D, Curtis L. Peer support: a theoretical perspective. Psychiatr Rehabil J 2001; 25: 134-141. doi:10.1037/h0095032

39 Penney D. Defining 'peer support': implications for policy, practice, and research. Sudbury, MA: Advocates for Human Potential Inc.; 2018.

40 Slade M, Amering M, Farkas M, Hamilton B, O’Hagan M, Panther G, Perkins R, Shepherd G, Tse S, Whitley R. Uses and abuses of recovery: implementing recovery-oriented practices in mental health systems. World Psychiatry 2014; 13: 12-20. doi:10.1002/wps.20084

41 Moran GS, Russinova Z, Gidugu V, Gagne C. Challenges experienced by paid peer providers in mental health recovery: a qualitative study. Community Ment Health J 2013; 49: 281-91. doi:10.1007/s10597-0129541-y
42 Stewart S, Watson S, Montague R, Stevenson C. Set up to fail? Consumer participation in the mental health service system. Australas Psychiatry 2008; 16: 348-53. doi:10.1080/10398560802047367

43 Thornicroft G, Slade M. Comparing needs assessed by staff and by service users: paternalism or partnership in mental health? Epidemiol Psychiatr Soc 2002; 11: 186-91. doi:10.1017/S1121189X00005704

44 Byrne L, Happell B, Welch T, Moxham LJ. 'Things you can't learn from books': teaching recovery from a lived experience perspective. Int $J$ Ment Health Nurs 2013; 22: 195-204. doi:10.1111/j.1447-0349.2012. 00875.x

45 Crossley N. Not being mentally ill: social movements, system survivors and the oppositional habitus. Anthropol Med 2004; 11: 161-80. doi:10. 1080/13648470410001678668

46 Yanos PT, Lysaker PH, Roe D. Internalized stigma as a barrier to improvement in vocational functioning among people with schizophrenia-spectrum disorders. Psychiatry Res 2010; 178: 211-13. doi:10.1016/j.psychres.2010.01.003

47 Rüsch N, Abbruzzese E, Hagedorn E, Hartenhauer D, Kaufmann I, Curschellas J, Corrigan PW. Efficacy of coming out proud to reduce stigma's impact among people with mental illness: pilot randomised controlled trial. Br J Psychiatry 2014; 204: 391-7. doi:10.1192/bjp.bp. 113.135772

48 Corrigan PW, Al-Khouja MA. Three agendas for changing the public stigma of mental illness. Psychiatr RehabilJ 2018;41: 1-7. doi:10.1037/ prj0000277

49 Corrigan PW, Morris S, Michaels P, Rafacz J, Rüsch N. Challenging the public stigma of mental illness: a meta-analysis of outcome studies. Psychiatr Serv 2012; 63: 963-73. doi:10.1176/appi.ps.201100529

50 Michaels PJ, Corrigan PW, Buchholz B, Brown J, Arthur T, Netter C, MacDonald-Wilson KL. Changing stigma through a consumer-based stigma reduction program. Community Ment Health $J$ 2014; 50: 395-401. doi:10.1007/s10597-013-9628-0 